Como citar: Carvalho, S. T. A., Neri, B. C. M., \& Farias, I. C. (2020). Comunidades Terapêuticas: um Relato de

Experiência sob o Olhar da Psicologia Comunitária. PSI UNISC, 4(2), 131-141. doi:

$10.17058 /$ psiunisc.v4i2.14811

\title{
Comunidades Terapêuticas: um Relato de Experiência sob o Olhar da Psicologia Comunitária
}

\author{
Comunidades Terapéuticas: un Informe de Experiencia Desde la Perspectiva de la \\ Psicología Comunitaria
}

\section{Therapeutic Communities: an Experience Report from the Perspective of Community Psychology}

\author{
Socorro Taynara Araújo Carvalho \\ Centro Universitário Inta (UNINTA), Sobral - CE/Brasil \\ ORCID: 0000-0002-4886-6706 \\ E-mail: carvalhotaynara44@gmail.com
}

Bruna Clézia Madeira Neri

Centro Universitário Inta (UNINTA), Sobral - CE/Brasil

ORCID: 0000-0003-3768-5843

E-mail: brunaclezia@gmail.com

\author{
Isabela Cedro Farias \\ Centro Universitário Inta (UNINTA), Sobral - CE/Brasil \\ ORCID: 0000-0002-5258-0946 \\ E-mail: behlafarias.if@gmail.com
}

\begin{abstract}
Resumo
Este trabalho é fruto de um relato de experiência que ocorreu durante a disciplina de Psicologia Comunitária, do curso de Psicologia de uma Instituição de Ensino Superior (IES). O relato é referente a uma visita técnica em uma Comunidade Terapêutica (CT) situada no interior de uma cidade de médio porte do Estado do Ceará. O principal objetivo deste trabalho é apresentar as percepções encontradas durante a visita em questão, estabelecendo uma conexão com o referencial teórico utilizado durante a disciplina de Psicologia Comunitária, propondo discussões acerca dessas entidades. Na comunidade em questão, nota-se uma percepção sobre esse ambiente como um lugar "perfeito", em que só depende do indivíduo a total recuperação da sua dependência química e esta deve ser baseada em um tripé que constitui a comunidade: convivência, trabalho e espiritualidade. Compreendemos a CT do presente estudo como uma amostra de CT's. Os resultados dessa análise foram essenciais para o processo de monitoria na disciplina de Psicologia Comunitária de uma das autoras desse artigo, pois a volta do campo permitiu uma reflexão crítica sobre o fenômeno das CT's, possibilitando a identificação de demandas e de possíveis situações que geram sofrimento psíquico nos sujeitos inseridos nesse espaço. Podemos considerar esse fenômeno como um retrocesso na luta antimanicomial, uma vez que esta tem como objetivo um tratamento que foge de todo modelo de exclusão, no qual o sujeito em sofrimento psíquico não deve ser segregado.
\end{abstract}

Palavras-chaves: Comunidades terapêuticas; Saúde mental; Reabilitação.

\begin{abstract}
Resumen
Este trabajo es el resultado de un informe de experiencia que ocurrió durante el curso de Psicología Comunitaria, del curso de Psicología de una Institución de Educación Superior (IES). El informe se refiere a una visita técnica a una comunidad terapéutica (CT) ubicada en el centro de una ciudad mediana en el estado de Ceará. El objetivo principal de este trabajo es presentar las percepciones encontradas durante la visita en cuestión, estableciendo
\end{abstract}

una conexión con el marco teórico utilizado durante la disciplina de Psicología Comunitaria, proponiendo discusiones sobre estas entidades. En la comunidad en cuestión, existe una percepción de este entorno como un lugar "perfecto", en el que la recuperación total de la dependencia química depende del individuo y esto debe basarse en un trípode que constituye la comunidad: convivencia, trabajo y espiritualidad. Entendemos la CT en este estudio como una muestra de CT. Los resultados 
de este análisis fueron esenciales para el proceso de monitoreo en la disciplina de Psicología Comunitaria por parte de uno de los autores de este artículo, ya que el regreso del campo permitió una reflexión crítica sobre el fenómeno de las CT, permitiendo la identificación de demandas y posibles situaciones que generan sufrimiento. psíquico en los sujetos insertados en este espacio. Podemos considerar este fenómeno como un revés en la lucha contra el asilo, ya que apunta a un tratamiento que escapa a cualquier modelo de exclusión, en el que el sujeto en angustia psicológica no debe ser segregado.

Palabras clave: Comunidades terapéuticas; Salud mental; Rehabilitación.

\begin{abstract}
This work is the result of an experience report that occurred during the discipline of Community Psychology, of the Psychology course of a Higher Education Institution (HEI). The report refers to a technical visit to a Therapeutic Community (CT) located in the middle of a medium-sized city in the State of Ceará. The main objective of this work is to present the
\end{abstract}

perceptions found during the visit in question, establishing a connection with the theoretical framework used during the discipline of Community Psychology, proposing discussions about these entities. In the community in question, there is a perception of this environment as a "perfect" place, in which the total recovery from chemical dependence depends on the individual and this must be based on a tripod that constitutes the community: coexistence, work and spirituality. We understand the CT in this study as a sample of CT's. The results of this analysis were essential for the monitoring process in the discipline of Community Psychology by one of the authors of this article, since the return of the field allowed a critical reflection on the phenomenon of TC's, enabling the identification of demands and possible situations that generate suffering psychic in the subjects inserted in this space. We can consider this phenomenon as a setback in the anti-asylum struggle, since it aims at a treatment that escapes any model of exclusion, in which the subject in psychological distress should not be segregated.

Keywords: Therapeutic communities; Mental health; Rehabilitation.

\section{Introdução}

O presente artigo trata-se de um relato de experiência, que ocorreu durante a disciplina de Psicologia Comunitária, do curso de Psicologia de uma Instituição de Ensino Superior (IES). A aula prática aconteceu durante uma visita a uma Comunidade Terapêutica (CT) situada no interior de uma cidade de médio porte do Estado do Ceará. A partir do exposto, o principal objetivo deste relato é apresentar as percepções encontradas durante a visita em questão, estabelecendo uma conexão com o referencial teórico trabalhado ao longo da disciplina, propondo discussões acerca dessas instituições.

Diferentes povos e culturas apresentam a presença de entorpecentes durante a sua constituição. $\mathrm{O}$ uso de substâncias psicoativas é feito por vários motivos, razões de cunho religiosos ou culturais, para facilitar a socialização e mesmo para se isolar (Machado \& Boarini, 2013). Ainda para as autoras, foi só no início do século XIX que vários países adotaram, em relação ao que hoje é considerado droga ilícita, medidas referentes ao campo da segurança e da Justiça. À dependência em relação a tais tipos de substâncias tornou-se também uma questão de saúde pública. No ano de 2004, inclusive, o Ministério da Saúde lançou a política para atenção integral de usuários de álcool e outras drogas (Brasil, 2003), indicando o paradigma da redução de danos nas ações de prevenção e tratamento. Souza, Souza, Souza, Abrahão e Fernandes (2016) apontam que tal documento criou uma fissura no discurso até então predominante nesse cenário uma vez que

a percepção dominante sobre o problema das drogas, até então marcada por um entendimento moral e criminal, implicava em uma estigmatização do usuário de drogas, contribuindo para o rechaço dessa clientela nos diversos serviços públicos, entre eles os de saúde. (Souza et al., 2016, p. 570).

Assim, em meados do século XX, com o processo da Reforma Psiquiátrica, surgem, no Brasil, os Centros de Atenção Psicossocial Álcool e Drogas (CAPS AD). Atualmente este é o equipamento de política pública responsável pelo atendimento a todas faixas 
etárias, especializado em transtornos pelo uso de álcool e outras drogas, pautado em uma lógica antimanicomial. Vale ressaltar que a multidisciplinaridade nesses serviços é de fundamental importância para que os atendimentos possam ser mais humanizados, visando à liberdade e autonomia das pessoas e não a reprodução de discursos (Alverga \& Dimenstein, 2006). Paralelamente ao surgimento dos CAPS AD, houve uma ação governamental que possibilitou a inserção de instituições conhecidas como Comunidades Terapêuticas (CT's), tratando-se do objeto de estudo do presente artigo.

Nesse sentido, as CT's, ao serem regulamentadas e inseridas na Rede de Atenção Psicossocial (RAPS) - a portaria $\mathrm{N}^{\mathrm{o}} 131$, de 26 de janeiro de 2012 instituiu incentivo financeiro de custeio para apoio aos Serviços de Atenção em Regime Residencial, incluídas as Comunidades Terapêuticas - viraram um tema polêmico, gerando discussões e debates que perduram até a contemporaneidade. As CT's fogem da lógica antimanicomial das políticas públicas de saúde mental pois, em sua grande maioria, apresentam como característica um tratamento sustentado no isolamento do sujeito. Além disso, a falta da atuação de equipes multiprofissionais no cuidado dos usuários também pode ser questionada.

Apresentaremos a seguir, os pressupostos da Psicologia Comunitária articulada à discussão do conceito de comunidade e a apropriação feita por tal termo por parte das CT's.

\section{O uso controverso do termo Comunidade}

A palavra comunidade possui origem no termo latim "communitas", que significa um "lugar em comum". As comunidades, durante a história, constituíram-se enquanto objeto de estudo em áreas como a Filosofia, Sociologia, Antropologia e Psicologia, que criaram conceitos e concepções de sujeito para essa categoria. Consequentemente, sempre houve divergências com relação às teorias sobre esse tema (Campos, 2011).
$\mathrm{Na}$ Psicologia, desde meados dos anos 60, no Brasil, vários psicólogos se movimentaram para a criação e manutenção de teorias e métodos visando uma prática em Psicologia Comunitária, na busca de uma deselitização da profissão e melhoria na qualidade de vida para as populações que vivem em comunidades (Campos, 2011). Vale ressaltar que nesse período aconteceu uma revolução paradigmática dentro do campo da Psicologia Social a partir de uma crítica às matrizes teóricas norte-americanas e europeias cuja implementação se tornou insustentável no cenário de desigualdades latino-americano que hora se apresentava.

Nessa perspectiva, a Psicologia Comunitária entende comunidade como espaços relacionais, onde a vida cotidiana é experienciada geograficamente ou psicossocialmente. $\mathrm{Na}$ comunidade, diversos sujeitos coexistem, gerando uma identidade coletiva, apresentando características em comum que são compartilhadas através das relações, sejam territoriais, culturais, psíquicas ou sociais (Sawaia, 2011).

Comunidade abrange todas as formas de relacionamento caracterizado por um grau elevado de intimidade pessoal, profundeza emocional, engajamento moral [...]. Sua força psicológica deriva em uma motivação profunda e realiza-se na fusão das vontades individuais, o que seria impossível numa união que se fundasse na mera conveniência ou em elementos de racionalidade. (Nisbet, 1974 como citado em Sawaia, 2011, p.41).

De acordo com Góis (2005), a intervenção da Psicologia Comunitária está relacionada à emancipação dos sujeitos que vivem na comunidade através de um processo de tomada de consciência de seu mundo histórico e cultural, gerando nas coletividades reflexões e afetos que permitem que as pessoas se percebam como transformadoras da realidade e de sua própria existência. 
Nesse sentido, em todos os processos que a Psicologia Comunitária produz enquanto prática, é necessário ser levado em consideração a promoção da autonomia e da cidadania dos sujeitos para um fazer democrático. Independente do modelo básico de trabalho em psicologia comunitária adotado, - tanto o clínico comunitário, que tem como objetivo cuidados em saúde mental, quanto o sócio comunitário, que enfoca uma visão sóciopolítica relacionada às questões sociais da comunidade - há, persistentemente, a tentativa de manter a promoção da autonomia e da cidadania dos sujeitos (Góis, 2005).

Além disso, a Psicologia Comunitária tem se tornado um campo teórico potente no contexto das Políticas Públicas, representadas por espaços que operam no cenário das comunidades, promovendo um cuidado que visa a liberdade e a emancipação dos sujeitos comunitários. É fundamental pontuar a Psicologia como uma prática baseada nos Direitos Humanos e na Reforma Psiquiátrica, com o dever ético de lutar contra qualquer tratamento que fuja destas perspectivas, como preconiza o Código de Ética Profissional do Psicólogo (Conselho Federal de Psicologia [CFP], 2005).

Neste âmbito, apresentamos as CT's enquanto organizações que se denominam 'comunidades', embora este termo seja compreendido com muita controvérsia quando trazemos este debate à tona. As CT's, apesar de carregarem o uso da palavra 'comunidade' em seu processo de identificação, não apresentam práticas que convergem para a compreensão deste termo a partir do ponto de vista da Psicologia Comunitária. Para Pitta e Guljor (2019), as CT's fazem parte de um modelo hegemônico no campo da assistência às pessoas em situação de drogadição, apresentando uma lógica de tratamento associada a exigência de abstinência total, a adoção de posturas moralizantes e a propostas análogas aos modelos asilares, em que os sujeitos devem permanecer isolados por longos períodos, impedidos de serem assistidos em seus territórios.
Tendo em vista, a pluralidade conceitual do termo comunidade, elegemos Zygmunt Bauman (2003) como um referencial importante, pois ele sistematizou conceitos sobre comunidades que consideramos pertinentes para a discussão do presente estudo. Para o autor, a palavra comunidade passa-nos a sensação de algo bom, um sentimento de aconchego, em que tudo parece perfeito. Dentro da comunidade não existem perigos, não há o que temer. As pessoas são boas, a confiança é a base dos relacionamentos e a união transparece.

E ainda: numa comunidade podemos contar com a boa vontade dos outros. Se tropeçarmos e cairmos, os outros nos ajudarão a ficar de pé outra vez. Ninguém vai rir de nós, nem ridicularizar nossa falta de jeito e alegrar-se com nossa desgraça. Se dermos um mau passo, ainda podemos nos confessar, dar explicações e pedir desculpas, arrepender-nos se necessário; as pessoas ouvirão com simpatia e nos perdoarão, de modo que ninguém fique ressentido para sempre. E sempre haverá alguém para nos dar a mão em momentos de tristeza. (Bauman, 2003, p.7).

Nesse contexto, podemos nos questionar: quem não quer viver em comunidade? Quem não quer essa sensação de "bem-estar" o tempo inteiro, no qual as pessoas verdadeiramente desejam lhe estender a mão para ajudar? Seriamos hipócritas em afirmar que nunca sonhamos com um lugar como esse. Por outro lado, levaríamos o nome de "tolos" se acreditássemos que existe esse "paraíso". Essa dicotomia entre aquilo que sonhamos e aquilo que realmente existe com relação à comunidade vai ser especificamente explicada por Bauman (2003, p.7):

Para nós em particular - que vivemos em tempos implacáveis, tempos de competição e de desprezo pelos mais fracos, quando as pessoas em volta escondem o jogo e poucos se interessam em ajudar-nos, quando em 
resposta a nossos pedidos de ajuda ouvimos advertências para que fiquemos por nossa própria conta, quando só os bancos ansiosos por hipotecar nossas posses sorriem desejando dizer "sim", e mesmo eles apenas nos comerciais e nunca em seus escritórios - a palavra "comunidade" soa como música aos nossos ouvidos. O que essa palavra evoca é tudo aquilo de que sentimos falta e de que precisamos para viver seguros e confiantes.

Diante disso entendemos o porquê dessa "comunidade sonhada" ser tão atraente e tão desejada, já que vivemos em uma sociedade que enaltece o individualismo. "Cada um por si" é uma das expressões mais conhecidas no senso comum do século XXI. Logo, essa comunidade sonhada a que Bauman se refere é uma esperança que todos queremos um dia alcançar, ao sair de relacionamentos volúveis (ou líquidos, usando as palavras do próprio autor) e encontrar algo sólido, sem jogos de interesses. Infelizmente, esse desejo de vida em comunidade é uma utopia, pois jamais conseguiremos chegar neste patamar. Essa comunidade sonhada sempre esteve no futuro, já que existe um preço caro a se pagar por viver em comunidade (Bauman, 2003).

De acordo com Freud (2010), viver em civilização é sempre uma troca. Ao escolher a liberdade é preciso abrir mão de certa segurança. Ao optar pela segurança deixamos para trás um certo grau de liberdade. Esse contraste é impossível de ser resolvido, pois se nos encontramos em comunidade, ganhamos "segurança" e perdemos liberdade. O fato é que nunca conseguimos ter os dois simultaneamente na mesma intensidade. Um vai sempre se sobressair.

Dessa forma, dentro de tal dilema, prevalece uma angústia de que não podemos fugir, gerada por muita liberdade e pouca segurança. Diante disso, o ser humano sempre vai buscar a comunidade sonhada, esse lugar inexplicável, onde tudo é tão aconchegante. Entretanto, essa busca jamais obterá sucesso, pois essa comunidade não existe. Ao se deparar com a comunidade realmente existente, percebemos que em nada se parece com os nossos sonhos e mais uma vez ocorrerá uma inevitável tensão. Nesse sentido, não importa qual seja a escolha, de alguma forma sairemos frustrados. Porém, continuaremos sonhando com a esperança de encontramos aquilo que nunca acharemos.

Apesar de ser estudado por vários autores, o termo 'comunidade' não se conserva fechado enquanto fenômeno psicossocial. É uma categoria que continua sendo pesquisada e permanece atual.

\section{Método}

Apresentamos aqui um breve relato de experiência que pretende entender um fenômeno específico em profundidade. Buscamos relacionar as percepções da observação da CT visitada com a teoria, processo necessário e fecundo ao se estudar a subjetividade de fenômenos sociais específicos como o que ora abordamos.

A disciplina de Psicologia Comunitária é ministrada no terceiro período do curso de Psicologia de uma IES, com a carga horária de 60 horas, sendo dividida em créditos teóricos e práticos. Durante a disciplina, os alunos participaram de algumas visitas técnicas a comunidades da região, com a proposta de gerar reflexões e criar projetos de intervenção psicossocial sobre esses espaços. A disciplina foi fundamental para fomentar nosso interesse pela área de atuação da Psicologia Comunitária, tanto que uma das autoras foi monitora voluntária da referida disciplina.

Fundamental pontuar que a CT analisada tem uma parceria com a IES na qual a disciplina em questão foi ministrada. Deste modo, a visita observacional e possíveis produções de trabalhos e projetos científicos referentes à CT foram consentidas pelos coordenadores do local.

A participação em uma visita específica a uma CT foi o ponto de partida para a escolha do objeto do presente estudo. Durante 
atividade, observamos de forma minuciosa o cotidiano dessa comunidade. Elegemos como principal ferramenta de captura das falas e impressões acerca do lugar o Diário de Campo, técnica cujo potencial é de extrema importância dentro de pesquisas qualitativas que pretendem averiguar fenômenos específicos a partir de observações empíricas. Através da descrição da experiência, pudemos retomar a experiência do momento vivido a partir de um ponto de vista analítico, pois durante o percurso da visita, muitas informações e percepções nos chegaram e era imprescindível manter o olhar sensível e atento àquele novo ambiente que nos era apresentado.

\section{Resultados e discussão}

Os resultados dessa análise foram essenciais para o processo criativo de construção da monitoria na disciplina de Psicologia Comunitária de uma das autoras desse artigo, pois a volta do campo permitiu uma reflexão crítica sobre o fenômeno das CT's, possibilitando a identificação de demandas e de possíveis situações que geram sofrimento psíquico nos sujeitos inseridos na CT do presente estudo.

A proposta avaliativa da disciplina em questão constituiu-se na produção de um projeto de intervenção a partir das visitas às comunidades. A turma foi dividida em equipes, que deveriam escolher uma das comunidades visitadas e criar um projeto de intervenção.

Escolhemos como base uma Intervenção Psicossocial, pois esta tem se mostrado uma metodologia de trabalho eficaz com grupos e apresenta em sua base a comunicação, fator que consideramos terapêuticos nesses espaços. São muitos os benefícios que ganhamos diante de uma intervenção como essa: trocas de experiências, aprendizagens, empatia, apoio emocional, favorecimento de sentimentos positivos, compartilhamento de histórias em comum, protagonismo e a emergência de soluções criativas para os problemas enfrentados no cotidiano. (Machado, 2004).
Nesse viés, construímos junto com os discentes projetos de intervenção psicossocial com a proposta de aplicação dos mesmos na referida comunidade e em outras que seguem modelo de atuação semelhante. Esses projetos foram construídos a partir de uma perspectiva do campo epistemológico da Psicologia Comunitária, baseados na autonomia e emancipação dos sujeitos. Para além da criação dos projetos, ficou em nós a inquietante demanda por pensar uma discussão mais aprofundada acerca dos meandros percebidos no cotidiano organizativo da comunidade em questão, bem como suas potenciais limitações diante da possibilidade de acolher sujeitos com histórias de vida distintas, que não podem ser reduzidas a um único modus operandi de intervenção.

\section{Comunidades Terapêuticas: políticas de acolhimento ou apagamento do sujeito?}

A CT visitada é situada em um distrito de uma cidade de médio porte do Estado do Ceará. Esta faz parte de uma rede de comunidades que estão espalhadas por todo o mundo. No Brasil, essas comunidades eclodiram no final do século XIX. A referida CT tem dez anos de história e seu trabalho ocorre através da convivência e da espiritualidade entre seus membros.

Nesse contexto, fizemos uma visita técnica, durante a disciplina de Psicologia Comunitária, do curso de Psicologia de uma IES, com o objetivo de qualificar o olhar em relação às comunidades terapêuticas. A proposta consistiu em uma observação minuciosa capaz de estabelecer um elo com as teorias e referências bibliográficas sobre esse tema, que é tão atual, mas que nem sempre é discutido com a relevância que merece.

A primeira percepção ao chegar na CT é de que o lugar é totalmente isolado, já que está inserido em uma localidade de um distrito afastado. Além disso, a CT em si é literalmente no "meio do nada", não há casas por perto, nenhum imóvel, apenas o cenário ermo do sertão. 
Dentro da comunidade, temos uma impressão cinematográfica do lugar, que é muito bonito. A natureza prevalece, com animais de várias espécies e o ambiente em si é acolhedor. Traz uma sensação de paz e tranquilidade. Em alguns momentos chegamos até a pensar: "eu moraria em um lugar como este!"’.

Os responsáveis pela comunidade nos apresentaram a todos os espaços, entre estes, as casas onde residem os moradores e locais para a "terapia". Terapia, para os membros da comunidade, é sinônimo de trabalho. Nesse sentindo, o trabalho é compreendido como algo que pode impulsionar a recuperação do sujeito e sua reinserção na sociedade, seja por meio das atividades na padaria, na marcenaria, nos currais ou no pomar. A administração apresenta um discurso sobre esse ambiente como um lugar "perfeito" em que só depende do indivíduo a total recuperação da dependência química. Conforme estudo de Santos (2016), na referida instituição, temos um modelo de convivência baseado em um tripé semelhante ao que a autora apresenta: convivência, disciplina e espiritualidade.

Assim, Bauman (2003, p.10) se faz muito preciso quando coloca que "há um preço a pagar pelo privilégio de 'viver em comunidade' - e ele é pequeno e até invisível só enquanto a comunidade for um sonho." A CT visitada, à primeira vista, é a comunidade sonhada descrita por Bauman. Tudo parece perfeito até o momento em que entram as "regrinhas básicas" para se viver em comunidade. Começa a aparecer, então, a Comunidade Realmente Existente, essa que enclausura o indivíduo e o faz perder sua autonomia.

Mediante isso, é fundamental salientar as "regras" que são impostas a esses sujeitos que se deslocam para uma comunidade terapêutica em busca de ajuda, de uma nova esperança e se deparam com um apagamento de quem eles mesmos são, coagidos a viver com uma rotina que até parece ter sentido, mas que gera processos de adoecimento no indivíduo. Nesse estudo, elencamos três categorias para discussão baseadas na observação do cenário da CT que apontavam para a constituição de uma estrutura que sustenta a comunidade em questão, sendo elas: convivência, trabalho e espiritualidade.

\section{Convivência}

A primeira regra que podemos frisar é com relação ao isolamento. Além da localização da comunidade ser de difícil acesso, acrescenta-se a questão de que o indivíduo não pode ter contato com o mundo externo. Para Fossi e Guareschi (2019), essa é uma característica muito peculiar dos modelos de Comunidade Terapêutica:

As comunidades terapêuticas em seu modelo residencial e de funcionamento estão pautadas na premissa de que, diante da impossibilidade de promover mudanças no indivíduo 'dependente químico', é necessário alterar o meio onde ele vive e retirá-lo da situação em que se dá o consumo de drogas. (p.76).

Caso o sujeito queira ouvir músicas, estas devem ser religiosas. Se quiser assistir televisão, está liberado para ver apenas filmes espirituais e essas atividades são feitas sob supervisão. A situação fica ainda mais complexa quando o "usuário" (como são chamados dentro de algumas comunidades) sofre uma restrição com relação ao convívio social, ou seja, não pode ver amigos, nem a família. Há exceções para algumas visitas, que ocorrem casualmente, e são limitadas a pessoas específicas, que possuem autorização do(a) responsável pelo residente. Tudo isso tem o objetivo de manter a abstinência, "desintoxicar o ser" e criar vínculos dentro da comunidade. Observamos aqui um dos termos de seu tripé, a "Convivência". Mas a convivência com quem, se não é possível estar com quem se ama, com quem realmente se quer perto?

Essa questão do isolamento viola as diretrizes sobre os direitos de pessoas com transtornos mentais, na Lei ${ }^{\circ} 10.216 / 2001$, que 
coloca a reforma psiquiátrica em ação no Brasil. No artigo $2^{\circ}$ acentua que a pessoa com esse tipo de problema deve "ser tratada com humanidade e respeito e no interesse exclusivo de beneficiar sua saúde, visando alcançar sua recuperação pela inserção na família, no trabalho e na comunidade."

\section{Espiritualidade}

Outro fator que encontramos na CT é a questão da "espiritualidade". Existe uma rotina que deve ser seguida meticulosamente com relação a isso. Independente do cunho religioso do indivíduo, ele tem que participar obrigatoriamente das celebrações diárias ocorridas na comunidade. Esse é um dos discursos mais defendidos pela CT, que o sujeito será "livre" das amarras da droga através do contexto religioso. Podemos notar isso quando encontramos diversas imagens sacras espalhadas por toda a comunidade, além de frases simbólicas se referindo à bíblia, que estão em várias partes das casas.

A liberdade de consciência e crença, assim como a prestação de assistência religiosa em entidades civis e militares de internação coletiva, bem como a vedação à privação de direitos por motivo de crença religiosa, constam entre os direitos e deveres individuais e coletivos previstos na Constituição de 1988 ( $\operatorname{art} .5^{\circ}$, incisos VI, VII e VIII). Deriva daí que, individualmente, cada cidadão ou cidadã pode escolher crença e afiliação a uma, a outra, ou a nenhuma religião, mas uma crença religiosa não pode levar à privação de direitos. (CFP, 2018, p. 79).

Dentro da CT, o sujeito perde sua autonomia, não tem o direito de escolher ou não participar de um ritual religioso, é submetido a uma crença, que muitas vezes, não se trata da sua. Nesse sentido, o sujeito perde até sua identidade cultural. Além disso, a religião é um saber que não deve se misturar com a saúde. A religião considera entre seus dogmas o assistencialismo e a caridade, cujo âmbito não é abordado no campo interdisciplinar da
Psicologia. Assim, podemos pensar, que técnicas estão sendo usadas como terapia para esses sujeitos?

\section{Trabalho}

Além da "convivência" e "espiritualidade", temos também o "trabalho". $\mathrm{Na}$ CT, eles chamam isso de Terapia Ocupacional, mas o termo sistematizado é Laborterapia. Assim todos os "usuários" devem acordar às cinco da manhã, participar da primeira celebração religiosa do dia e logo depois permanecer na "terapia", com algumas pausas para atividades devocionais. À noite, desfrutam o "lazer", que geralmente trata-se de um filme de cunho religioso. A terapia ocorre na padaria, com o feitio de pães; na marcenaria, com a criação de objetos, em sua maioria decorativos; no pomar e currais, cuidando das plantações e dos animais ou dentro de casa, fazendo as tarefas domésticas. Através dessa "terapia", os indivíduos podem se manter e se sustentar dentro da comunidade, já que não há outras pessoas para fazer estes serviços.

Um dos discursos mais verbalizados na sociedade é de que "o trabalho dignifica o homem". Isso é colocado nas comunidades como algo bom, porém devemos questionar em que condições esses procedimentos ocorrem, pois as funções diárias de cada indivíduo são uma regra que deve ser cumprida rigorosamente nesses lugares. É nesse sentido que o Conselho Federal de Psicologia (2017, p.18) aponta que a "chamada 'laborterapia' encobre práticas de trabalho forçado e em condições degradantes - práticas que trazem fortes indícios de crime análogo à escravidão".

Portanto, as comunidades terapêuticas, especificando aqui a CT em estudo, fogem da Lei da Reforma Psiquiátrica, uma vez que esta foi construída em contraposição às formas de exclusão e exploração a pessoas com transtornos mentais, e aqui permanece incluso o sujeito em situação de toxicodependência.

Assim, notamos um caráter asilar dentro dessas comunidades que enclausuram o indivíduo, impelido a seguir rotinas exaustivas 
de trabalho, além de sofrer uma possível culpabilização infligida através da religião pelo descumprimento de condutas moralizantes que fazem parte dos princípios da CT. Dentro desses lugares o indivíduo não tem direito a fazer escolhas espontâneas, vive à mercê daquilo que lhe é imposto. Apesar de ter clareza acerca da possibilidade de sair da CT quando quiser, o sujeito que lá ingressa acaba se tornando refém de práticas normatizadoras que coíbem sua autonomia.

Fica claro o quanto a Psicologia Comunitária se faz essencial para refletirmos sobre tais práticas, que se constituem não apenas como aprisionadoras, mas, essencialmente, limitantes para a tomada de consciência de indivíduos adoecidos em processo de recuperação.

\section{Considerações Finais}

Diante do exposto, compreendemos a CT do presente estudo como uma amostra de CT's. Podemos considerar esse fenômeno como um retrocesso na luta antimanicomial, pois esta tem como objetivo um tratamento que foge de todo modelo de exclusão, uma vez que o sujeito em sofrimento psíquico não deve ser segregado, nem retirado de suas relações sociais.

O caráter asilar é notório quando percebemos o isolamento produzido por essas organizações, além da restrição ao convívio social e da incomunicabilidade por meio de visitas limitadas. $\mathrm{O}$ indivíduo perde sua subjetividade sem que o perceba, pois não tem direito de escolha dentro desses espaços.

Nessa perspectiva, o preço de viver em uma CT é passar por uma violação de liberdade religiosa, na qual a culpabilização moral está no centro dessas reuniões de espiritualidade que buscam a "cura". Fazer parte dessa comunidade é ser persuadido a trabalhar e ser levado a acreditar nisso como uma forma de "terapia". Para inserir-se novamente em sociedade é necessário ao sujeito ter como virtude a "coragem para trabalhar". Um projeto terapêutico individual que considera as singularidades do sujeito não é aqui levado em consideração.

Além desses fatores que violam leis trabalhistas e ferem a Constituição Brasileira como um Estado laico, existem outras deficiências que inviabilizam o tratamento, como a precariedade com relação a equipe de trabalho encontrada dentro da CT's, já que locais que trabalham com saúde mental precisam de uma equipe multidisciplinar. $\mathrm{Na}$ CT, não encontramos tais profissionais, apenas alguns voluntários, que geralmente são líderes religiosos.

Nesse contexto, é fundamental questionar os modos de fiscalização a essas entidades, pois as mesmas estão inseridas na RAPS, que prestam um serviço público de saúde no Brasil. Outrossim, as CT's recebem investimento do governo, porém não seguem as matrizes da Reforma Psiquiátrica, que é a base dos serviços de Políticas Públicas em saúde mental no Brasil. Portanto, o Estado possui a responsabilidade de intervir nesses órgãos que negligenciam o serviço de saúde nas mais diversas formas aqui já citadas.

As Políticas Públicas no Brasil representam a efetivação de diversos direitos, entretanto ainda passam por um processo de reestruturação e adaptação, no qual os profissionais estão construindo e transformando o fazer dessa área. Diante disso, destacamos a importância do Estado ao investir nesses órgãos, que muitas vezes ficam esquecidos, como o CAPS AD, um equipamento especializado no tratamento de pessoas em situação de drogadição e que possui uma forma de intervenção distinta a das Comunidades Terapêuticas.

Os CAPS AD apresentam uma lógica de tratamento na qual o sujeito não perde sua autonomia, e não é referido como um "coitado", mas participa ativamente da terapia, faz seu tratamento e continua em seu trabalho, em seu meio social, não sofrendo nenhum tipo de exclusão. O sujeito é recebido de forma humanizada por uma equipe multiprofissional que cria um projeto terapêutico, levando em 
consideração as singularidades do indivíduo. $\mathrm{O}$ mesmo discute toda a proposta diretamente com os profissionais, dando ênfase às suas questões. Portanto, esse equipamento tem se mostrado muito efetivo.

Inclusive, reiteramos a importância de ressaltar uma ferramenta extremamente potente dentro da Psicologia Comunitária: a intervenção psicossocial. Esta, através de trabalho com grupos, possibilita o manejo de questões que consideramos fundamentais no processo de libertação dos sujeitos das estruturas opressoras nas quais estão inseridos. Um dos desdobramentos desse relato de experiência foi a orientação na criação de projetos psicossociais na disciplina de Psicologia Comunitária.

Finalmente, aqui deixamos a seguinte questão: Até quando continuaremos repetindo os mesmos erros do passado? Todos os profissionais da saúde têm o dever de denunciar, de criticar e questionar essa forma enclausurada de cuidado representada pelas Comunidades Terapêuticas.

\section{Referências}

Alverga, A. R., \& Dimenstein, M. (2006). A reforma psiquiátrica e os desafios desinstitucionalização da loucura. Interface - Comunic., Saúde, Educ., 10(20), 299-316. doi: 10.1590/S1414-32832006000200003

Bauman, Z. (2003). Comunidade: a busca por segurança no mundo atual. (P. Dentzien. Trads). Rio de Janeiro, RJ: Zarah.

Brasil. Ministério da Saúde. Secretaria Executiva. Coordenação Nacional de DST e AIDS. (2003). A política do Ministério da Saúde para atenção integral a usuários de álcool e outras drogas. Brasília, DF.

Campos, R. D. F. (2011). Introdução: a psicologia social comunitária. In R. Campos (Eds.), Psicologia social comunitária: da solidariedade à autonomia. (20a. ed., pp. 9-15). Petrópolis, RJ: Vozes.

Conselho Federal de Psicologia [CFP]. (2018). Relatório da Inspeção Nacional em Comunidades Terapêuticas. Recuperado de https://site.cfp.org.br/wpcontent/uploads/2018/06/Relat\%C3\%B3rio -da-Inspe\%C3\%A7\%C3\%A3o-Nacionalem-ComunidadesTerap\%C3\%AAuticas.pdf

Conselho Federal de Psicologia. (2005).

Código de ética profissional dos psicólogos. Brasília: CFP. Recuperado de http://site.cfp.org.br/wpcontent/uploads/2012/07/codigo-de-eticapsicologia.pdf
Fossi, L. B., \& Guareschi, N. M. F. (2019). Aspectos Punitivos do Tratamento nas Comunidades Terapêuticas: O Uso de Drogas como Dano Social. Revista Psicologia e Saúde, 11(1), 73-88. doi: 10.20435/pssa.v0i0.611

Freud, S. (2010). O mal-estar na civilização, novas conferências introdutórias e outros textos (P. C. Souza. Trads.). São Paulo, SP: Cia. Das Letras.

Góis, C. W. D. L. (2005). Psicologia Comunitária: atividade e consciência. Fortaleza, CE: Instituto Paulo Freire de Estudos Psicossociais.

Lei $n^{o} 10.216$, de 6 de abril e 2001. Dispõe sobre a proteção e os direitos das pessoas portadoras de transtornos mentais e redireciona o modelo assistencial em saúde mental. Recuperado de http://www.planalto.gov.br/ccivil_03/lei s/leis_2001/110216.htm

Machado, L. V., \& Boarini, M. L. (2013). Políticas sobre drogas no Brasil: a estratégia de redução de danos. Psicologia: Ciência e Profissão, 33(3), 580-595. doi: 10.1590/S1414-98932013000300006

Machado, M. N. da M. (2004). Práticas psicossociais: pesquisando e intervindo. Belo Horizonte, MG: Edições do Campo Social.

Pitta, A. M. F., \& Guljor, A. P. (2019). A violência da contrarreforma psiquiátrica no Brasil: um ataque à democracia em tempos de luta pelos direitos humanos e justiça 
social. Cadernos do CEAS: Revista crítica de humanidades, (246), 6-14. doi: 10.25247/2447-861X.2019.n246.p6-14

Portaria $n^{\circ} 131$, de 26 de janeiro de 2012. Institui incentivo financeiro de custeio destinado aos Estados, Municípios e ao Distrito Federal para apoio ao custeio de Serviços de Atenção em Regime Residencial, incluídas as Comunidades Terapêuticas, voltados para pessoas com necessidades decorrentes do uso de álcool, crack e outras drogas, no âmbito da Rede de Atenção Psicossocial. Recuperado de http://bvsms.saude.gov.br/bvs/saudelegis /gm/2012/prt0131_26_01_2012.html.

Santos, M.P.G. (2016). Comunidades

Terapêuticas: unidades de privação de liberdade? Boletim de Análise PolíticoInstitucional. (10), 39-46. Recuperado de: http://www.ipea.gov.br/portal/index.php?op tion $=$ com_content $\&$ view $=$ article $\&$ id $=2966$ 4\&Itemid $=6$

Sawaia, B. B. (2011). Comunidade: A apropriação científica de um conceito tão antigo quanto a humanidade. In R. Campos (Eds.) Psicologia social comunitária: Da solidariedade à autonomia. (20a. ed., pp. 29-43). Petrópolis, RJ: Vozes.

Souza, L. F., Souza, A. C., Souza, E. O., Abrahão, A. L., \& Fernandes, F. L. (2016). A universidade como parceira na formação diferenciada para o cuidado aos usuários de drogas. Pesquisas e Práticas Psicossociais, 11(3), 570-582. Recuperado de http://pepsic.bvsalud.org/scielo.php?script= sci_arttext\&pid=S18098908201600030000 $4 \& \operatorname{lng}=\mathrm{pt} \& \mathrm{t} \operatorname{lng}=\mathrm{pt}$

\section{Dados sobre as autoras:}

- Socorro Taynara Araújo Carvalho: Acadêmica do curso de Psicologia pelo Centro Universitário INTA (UNINTA).

- Bruna Clézia Madeira Neri: Docente do curso de Psicologia do Centro Universitário INTAUNINTA, Graduada em Psicologia pela Universidade Federal do Ceará - UFC Campus Sobral. Mestre em Psicologia Social e Institucional pela Universidade Federal do Rio Grande do Sul.

- Isabela Cedro Farias: Docente do curso de Psicologia do Centro Universitário INTAUNINTA, Graduada em Psicologia pela Universidade Federal do Ceará - UFC Campus Sobral. Mestre em Saúde da Família pela Universidade Federal do Ceará. direitos autorais para os artigos publicados são do autor, com direitos do periódico sobre a primeira publicação. Os autores somente poderão utilizar os mesmos resultados em outras publicações indicando claramente este periódico como o meio da publicação original. Em virtude de sermos um periódico de acesso aberto, permite-se o uso gratuito dos artigos em aplicações educacionais e científicas desde que citada a fonte conforme a licença CC-BY da Creative Commons. 